\title{
Study on Emotional Words and Favorableness Associated with the Faces of Women in Their 60s
}

\author{
Ae Kyung $\mathrm{Kim}^{\dagger}$ and Yun Kyoung $\mathrm{Oh}^{1)}$ \\ Dept. of Beauty Care, Tongmyong University; Pusan, Korea \\ ${ }^{1)}$ Dept. of Cosmetology, Changshin University; Changwon, Korea
}

\begin{abstract}
This study, using the free language association method, examined the characteristics of emotional words of respondents who were exposed to facial photos of women in 60 s, and favorableness and favorable styles of them. To analyze mood characteristics on the faces, they were divided into positive mood words and negative mood words. Following previous researches, they were divided into introversion, extraversion, and ambiversion. It was found that the proportion of positive emotional words respondents used was $37 \%$, and that of negative ones was $63 \%$, demonstrating that respondents are more likely than not to get the negative impressions from the faces of their contemporaries. The characteristics of the words consists of $38 \%$ introversion, $47 \%$ extraversion, and $14 \%$ ambiversion. And, respondents used the words like 'beautiful' and 'good-looking' to the stimuli to which they felt favorable, and 'ill-tempered' and 'stubborn' to the stimuli to which they felt unfavorable. Third, the most favorable style to both male and female respondents in 60 s were sentimental and good-mannered. They generally favor women who are soft and caring, and dislike talkative, snobbish, and thick make-up women. The analysis results in this paper may help image making and personal relations. Further study needs to expand the survey area to ensure more significant influence on the social life and interpersonal relationship of senior citizens.

Key words : emotional words, women in 60 s, face
\end{abstract}

\section{Introduction}

Facial expression is expressed through emotion(Huh, 1995), and emotion includes unique behavior tendency or personal experiences such as fear, anger, or sorrow(Greeberg \& Paivio, 2003). From human faces, one can grasp not only unique expressions, but expressions formed by life experiences, and human expressions include basic expressions like sorrow, anger, gladness, fear, hate, and surprise, etc.(Conley et al., 1982). Emotions one can grasp from the face of the other person is the combination of practical elements, feeling, and emotional elements, and the concept of image used in daily life can be understood as image, mental image, and video image, and the emotion one holds for an object can be called as the subjective knowledge on the object(Hong, 1988). And, as the impression of the other person is formed through his outward appearance, behavior, and the context of situations, or accidents, the face when one meets the other person at the intial stage is an important variable which affects recognition with other person(Kaiser, 1985). Impression of a person varies depending on emotions revealed in the face out of the overall outward appearance. As the proportion of the elderly population increases, and

$\uparrow$ Corresponding author; Ae Kyung Kim

Tel. +82-51-629-3542, Fax. +82-51-629-2019

E-mail: yeskak@daum.net their external activities become more active, the impressions shown in their faces inevitably become an important issue. Especially, the faces of those in their $60 \mathrm{~s}$ reveal personal characters and emotions formed by personal experiences. Though the formation of emotion is influenced by personal experiences, it is psychological mechanism human beings share, and part of our lives we feel every day(Huh, 2000). Therefore, this study, using the faces of those in $60 \mathrm{~s}$ as the stimuli, tries to help those in $60 \mathrm{~s}$ give good images of them to others and present themselves effectively in their human relations by analyzing the characteristics of emotional vocabulary recognized in the face, and examining the styles from which those in 60 s get good feeling.

\section{Theoretical background}

\subsection{Facial mood}

Mood is the term designating extremely complex and various phenomena generated by combination of subjective experiences, expressed actions, and neuro-chemical activities. Mood can in various ways accompany consciousness on personal environment or situation, physical response, access and avoidance actions. Mood is psychological mechanism human beings share, and part of our lives(Huh, 2000). According to Park and Min(2005), physiological indicators of emotion include mainly the changes of the autonomous nervous system such as brain waves, electrocardiogram, ocu- 
lar movement, breath, skin temperature, and blood pressure, etc., and, even if they have merits like being objective indicators and reflecting unrecognized emotional state, it is not easy to differentiate individual emotions, and to get reliable measurements of them. While verbal expression through facial expression is affected by the culture the person belongs to, situation and personality, since it is possible to express internal emotional state in various and delicate ways, they are the most advanced emotional expressions. Kim (2003) analyzed the relationship between facial impression and physical characteristics of face, and examined the effect of facial impression on the judgement of cognitive similarity. She implied that, since facial impression is used as psychological structure reflecting facial feature, one is likely to treat facial impression together with facial information. She said that concrete language and action are excluded at the front face, not at the side face, and that the more a face shows personality with clear facial features, the more correctly one can see one's inner world. Park et al.(2002), in their research on structural concept of beautiful face, said that challenging feel, Western feel, hard feel, cute feel, and clean fell, etc. are physical characteristics in the relationship between individual sentiment and faces. According to Lee and Lee(2003), the ideal beauty for those in 20 s can be expressed as the words like 'confident', 'dignified', and 'showing personality', etc. and those for those of 60s are described as 'healthy', 'beautiful', 'leisurely', 'elegant', and 'comfortable, etc. Lee et al.(2003) suggests 4 dimensions in recognizing facial impressions: docile-fierce; good impressionbad impression; intellectual-not intelligent, or smart-dull; gentlemanlike-frivolous; feminine-masculine. Lee et al.(2001) argued that, in forming images of Korean women, the following four can be important standards: sharp-Western; dull-Oriental; masculinestrong; feminine-cute. Oh(2006) mentioned that attractive and credible image of news anchor is an important element to persuade the audience. Jo(2004) examines the influence of physical characteristics of face on inner mood, and analyzes whether there is difference in evaluation of facial impressions between Korea and Japan.

\subsection{Study on Emotional Word}

In the characteristics of words, there are two aspects-psychological value and sensual value, and, depending on the subjects who feel them, they can be divided into subjective ones and objective ones(Kim et al., 1998), and characteristics one can feel from words can be divided into internal ones and external ones, considering what judges and accepts them. Psychologist Carl Jung, in his theory of personality type, classifies human personality into introversion and extraversion, depending on the directions of fundamental thought and behavior(Lee et al., 2001). Introvert puts emphasis on mental and conceptual aspects, but extrovert focuses on physical aspects shown in appearance. Introversion is expressed through common knowledge, thought, personality, value, and special knowledge, and extraversion means body image expressed as appearance and clothing presentation, and material aspects which are perceived immediately as soon as one looks at the external features(Lee \& Han, 2003). On the other hand, Lee and Lee(1990), to examine mood characteristics in attributes of adjectives, extracted 72 words from the vocabulary related with mood, and broadly classified them into active mood like gladness, anger, fear, and irritation, etc. and passive mood like sorrow, agony, and despair, etc. They subdivided active mood into pleasant mood and unpleasant mood, and again subdivided pleasant into unspecific activation and specific pleasantness, and subdivided specific pleasantness into extraversion and introversion. The research by Lee and Lee(2003) analyzed the words by referencing a variety of dictionaries including the Korean Language Classification Dictionary, Korean Language Source Dictionary, Korean Adjective Dictionary Yonsei Korean Dictionary, and the Korean BIg Dictionary in order to verify the feasibility of the linguistic meaning of words. They analyzed the words by dividing them into inner-oriented, outeroriented, and dual-oriented words around the subjects of determination. Furthermore, Kim(2012) analyzed the words by classifying into positive and negative words as an approach expanding the research of Lee and Lee(2003).

Lee et al.(2003) divided 20 mood words into positive mood and negative mood, and they included the following words as belonging to the former: vivacious, passionate, energetic, proud, powerful, interested, excited, resolute, and attentive, etc. They did the followings as belonging to the latter: nervous, oversensitive, painful, hurt, fearful, hostile, impatient, frightened, agile, guilty, and shameful, etc. Kim et al.(1998), in their study on emotional vocabulary related with perception on facial expressions, made respondents write words, and selected 22 words, and extracted dimension of pleasantness and unpleasantness and awakening from words like gladness, joyfulness, happiness, tension, and tiredness. And, specific emotion of an individual is revealed in characteristic facial expressions, and other people can be aware of his or her emotional condition through the facial expression(Izzard, 1977). Reasoning of emotion from facial expression means being able to grasp general aspects on how much happy the person is, how miserable or how much relaxed the person is, rather than finding out concrete emotional conditions. In most studies, those emotions are summarized into negative and positive emotions(Kim, 2002). Lee and Lee(2003) divides mood words into positive and negative words. She includes vivacious, passionate, energetic, proud, powerful, and interested in the former category, and irritated, oversensitive, pain- 
ful, hurt, fearful, and hostile in the latter category. Therefore, emotional words one can get from faces of others simply reveal internal emotions to external elements, and they are emotional vocabulary serving as subjective and objective hints to evaluate other people.

\section{Methods}

The photo stimulus is what was used by $\operatorname{Kim}(2012)$, and, using the free language association method, those stimuli were given to 150 male and female elderly in Busan. Twenty-two pictures from the research by $\operatorname{Kim}(2012)$ were reduced by half and presented. The free language association method was conducted from April 6 $\sim 20,2011$. The respondents selected High, Medium, and Low as their preference of those pictures and wrote the preferred style. One hundred fifty questionnaires for preference and preferred style and 150 questionnaires for emotional words were collected. Finally, 132 total questionnaires were selected, not including questionnaires that did not comply with the survey standards. 63 male and 83 female respondents submitted questionnaires. The data was analyzed by content analysis and frequency analysis. Favorableness and favorable style were investigated at the same time. Favorableness was divided into three levels-high, middle, and low. Among the data of 150 persons, 132 cases were used for analysis excluding improper ones. To analyze mood characteristics on the faces, they were divided into positive mood words and negative mood words. Following previous researches by Lee and Lee(2003) and Kim(2012), they were divided into introversion, extraversion, and ambiversion. Introversion is expressed by psychological and con- ceptual judgement, and ambiversion involves both introversion and extraversion.

\section{Findings and discussion}

\subsection{Analysis of emotional words showing in the faces of women in $60 \mathrm{~s}$}

The total number of emotional words used by respondents to describe their impression about the faces of women in $60 \mathrm{~s}$ was 1872 , which were sorted out into 131 kinds of words by merging similar words.

In the final analysis, the number of words used 9 or more times was 1119 in 47 kinds. Collected words about the faces of women in 60 s were divided into positive emotional words and negative emotional words, and they were divided into three types: introversion, extraversion, and ambiversion(Table 1, 2).

Generally speaking, the most frequently used term among all the emotional words regarding the faces of women in 60s was 'worried', followed by 'ill-tempered', 'common', 'stubborn', 'strong', 'fiercetempered', 'melancholy', 'benign', 'offensive', 'scary', 'pleasing', 'rigorous', and 'sharp' in descending order. The above words took up $54 \%$ of all words applied to the faces of women in $60 \mathrm{~s}$.

Positive emotional words like 'common', 'benevolent', 'look pleasing', and 'caring' took up $37 \%$ of the all words, and they were of 24 kinds. Negative emotional words like 'worried', 'ill-tempered', 'stubborn', 'strong', and 'fierce-tempered', etc. took up $63 \%$ the all words, of 23 kinds.

Introversive words like 'worried', 'stubborn', 'melancholy',

Table 1. Comparative words of positive emotion and negative emotion in women faces of $60 \mathrm{~s}$

\begin{tabular}{|c|c|c|c|c|}
\hline Category & & Words(frequency) & & $\begin{array}{l}\text { Total } \\
\mathrm{n}(\%)\end{array}$ \\
\hline Positive & $\begin{array}{c}\text { common }(57) \\
\text { benign }(38) \\
\text { look pleasing(36) } \\
\text { caring }(25) \\
\text { active }(22) \\
\text { comfortable(21) } \\
\text { warmhearted(20) } \\
\text { bright }(19)\end{array}$ & $\begin{array}{c}\text { plain(18) } \\
\text { mild(18) } \\
\text { sociable(17) } \\
\text { good-natured(11) } \\
\text { pretty(13) } \\
\text { amiable(10) } \\
\text { devoted(10) } \\
\text { soft }(9)\end{array}$ & $\begin{array}{l}\text { uncontentious(9) } \\
\text { composed(9) } \\
\text { familiar(9) } \\
\operatorname{prick} \text { up(9) } \\
\operatorname{good}(9) \\
\text { accommodating(9) } \\
\text { good tempered(9) } \\
\text { premeditative(9) }\end{array}$ & $\begin{array}{c}24 \\
(37)\end{array}$ \\
\hline Negative & $\begin{array}{c}\text { worried(75) } \\
\text { ill-tempered(63) } \\
\text { stubborn(54) } \\
\text { strong(50) } \\
\text { fierce-tempered(45) } \\
\text { melancholy }(42) \\
\text { offensive }(38) \\
\text { scary }(37)\end{array}$ & $\begin{array}{l}\text { rigorous(36) } \\
\operatorname{sharp}(35) \\
\operatorname{greedy}(25) \\
\text { tough(20) } \\
\text { disgusting(20) } \\
\text { irritant(19) } \\
\text { sad(18) } \\
\text { brusque(18) }\end{array}$ & $\begin{array}{c}\text { cold(18) } \\
\text { inexpressive }(16) \\
\text { ordeal }(15) \\
\text { like heroine(15) } \\
\text { dark(13) } \\
\text { country }(10) \\
\text { stuffy }(9)\end{array}$ & $\begin{array}{c}23 \\
(63)\end{array}$ \\
\hline $\begin{array}{l}\text { Total } \\
\mathrm{n}(\%)\end{array}$ & & & & $\begin{array}{c}47 \\
(100)\end{array}$ \\
\hline
\end{tabular}

*Total frequency : 1119 
Table 2. Characteristics of emotion words in women faces in $60 \mathrm{~s}$

\begin{tabular}{|c|c|c|c|c|}
\hline Category & Words(frequency) & & & $\begin{array}{l}\text { Total } \\
\mathrm{n}(\%)\end{array}$ \\
\hline Introversion & $\begin{array}{c}\text { worried(75) } \\
\text { stubborn(54) } \\
\text { melancholy(42) } \\
\text { benign( } 38) \\
\text { caring( } 25) \\
\text { greedy }(25)\end{array}$ & $\begin{array}{c}\text { tough(20) } \\
\text { warmhearted(20) } \\
\text { sad(18) } \\
\operatorname{cold}(18) \\
\operatorname{dark}(13) \\
\operatorname{mild}(18)\end{array}$ & $\begin{array}{c}\text { good-natured(11) } \\
\text { devoted(10) } \\
\operatorname{good}(9) \\
\text { accommodating(9) } \\
\text { premeditative(9) } \\
\text { stuffy }(9)\end{array}$ & $\begin{array}{c}18 \\
(39)\end{array}$ \\
\hline Extraversion & $\begin{array}{c}\text { ill-tempered(63) } \\
\text { strong(50) } \\
\text { fierce-tempered(45) } \\
\text { offensive( } 38) \\
\text { scary }(37) \\
\text { rigorous(36) } \\
\text { look-pleasing(36) } \\
\text { sharp }(35)\end{array}$ & $\begin{array}{c}\text { active }(22) \\
\text { comfortable(21) } \\
\text { disgusting(20) } \\
\text { sociable(17) } \\
\text { good-tempered(9) } \\
\text { inexpressive (16) } \\
\text { ordeal(15) } \\
\text { like-heroine(15) }\end{array}$ & $\begin{array}{c}\operatorname{pretty}(13) \\
\text { country }(10) \\
\text { amiable }(10) \\
\text { uncontentious }(9) \\
\text { soft( } 9)\end{array}$ & $\begin{array}{c}21 \\
(47)\end{array}$ \\
\hline Ambiversion & $\begin{array}{c}\text { brusque(18) } \\
\text { common(57) } \\
\text { bright(19) }\end{array}$ & $\begin{array}{c}\text { irritant(19) } \\
\text { plain(18) } \\
\text { prick up(9) }\end{array}$ & $\begin{array}{l}\text { composed(9) } \\
\text { familiar(9) }\end{array}$ & $\begin{array}{c}8 \\
(14)\end{array}$ \\
\hline $\begin{array}{l}\text { Total } \\
\mathrm{n}(\%)\end{array}$ & & & & $\begin{array}{c}47 \\
(100)\end{array}$ \\
\hline
\end{tabular}

'benign', 'caring', and 'greedy' took up 38\% of the all words, and extraversive words like 'ill-tempered', 'strong', 'fierce-tempered', 'offensive', and 'scary', etc. took up $47 \%$ of the all words. And, ambiversive words like 'brusque', 'common', 'bright', 'irritant' took up $14 \%$ of the all words.

In the research of $\mathrm{Kim}(2012)$, among respondents in their 20s, the most frequently used impressions from the faces of women in 60 s were 'look tired' and 'scary'. In this research among respondents in 60s, they were 'worried' and 'ill-tempered'. In the choice of positive and negative emotional words, while the most frequently cited words for the faces of women in 60 s among respondents in their 20s were 'good-natured', 'look young', 'look tired', 'scary', and 'melancholy' in descending order, those among respondents in 60s of this research were 'common', 'benevolent', 'look pleasing', and 'worried'. In the kinds of words, while respondents in 20s used 17 positive kinds of words and 29 negative kinds of words, respondents in 60 s used 24 positive ones and 23 negative ones. In short, while those in 20 s tend to interpret facial expressions of women in 60 s more negatively than not, those in 60 s balance positive and negative interpretation on facial expressions of women in 60s. In the characteristics of words, respondents in 20 s chose 10 introversive words like 'melancholy', and 'good-natured'; 28 extraversive words like 'scary' and 'strong', etc.; 9 ambiversive words like 'look tired' and common. On the other hand, respondents in 60s chose 18 introversive words like 'worried' and 'stubborn', etc.; 21 extraversive words like 'ill-tempered' and 'strong', etc.; 8 ambiversive words like 'common' and 'bright', etc. There was not much difference in the choice of those in 60 s between introversion focusing on psychological and ideal and extraversion emphasizing physical things.

Therefore, we can assume that, while those in 20 s tend to get biased impressions on the faces of old ladies, those of $60 \mathrm{~s}$ can grasp the facial expressions of those of their contemporaries more minutely, and look at inner and outer aspects of the facial expressions.

\subsection{Analysis of favorableness respondents get from} the faces of women in their $60 \mathrm{~s}$

This study examined the favorableness of respondents in their $60 \mathrm{~s}$ to stimuli of facial photos of women in 60s. Table 3 shows favorableness was classified into three levels: high, middle, and low. High responses were expressed as emotional words like 'pretty', 'looking-pleasing', and 'soft', and other emotional terms like 'benign', 'comfortable', and 'caring', etc. Low responses were expressed with emotional terms like 'ill-tempered', and 'stubborn',

Table 3. A degree attractive in women faces in $60 \mathrm{~s}$

\begin{tabular}{lcccccccccccc}
\hline Stimuli & & 2 & 3 & 4 & 5 & 6 & 7 & 8 & 9 & 10 & 11 & 12 \\
\hline High & 3 & 5 & 23 & 14 & 0 & 42 & 5 & 21 & 0 & 15 & 32 & 125 \\
Middle & 61 & 109 & 118 & 96 & 44 & 102 & 89 & 113 & 88 & 102 & 99 & 20 \\
Low & 86 & 36 & 9 & 40 & 106 & 6 & 56 & 16 & 62 & 33 & 19 & 5 \\
\hline
\end{tabular}


Table 4. Analysis of favorableness styles of women in $60 \mathrm{~s}$

\begin{tabular}{|c|c|c|}
\hline Sex & & Style \\
\hline \multirow{2}{*}{ Male } & Favorable & $\begin{array}{l}\text { beautiful(13), good-mannered(10), pure(9), good-natured(8), prosperous-looking(8), sentimental(8), soft(8), caring(7), } \\
\text { smiling(6), intellectual(6), maternal love(6), cultured(4), hearkener(4), dutiful(4), understanding(4), clean-skin(3), } \\
\text { faithful(3), skillfu-cooker(3), charming(3), taciturn-person (3), wit(2), honest(2), cheerful(2), slim(2), healthy(2), } \\
\text { feminine(2), plain, tender, wise, clean, dignified, self-administrated, positive, neat, smart, longsuffering, } \\
\text { well-fed, individual, respectfully, sexy }\end{array}$ \\
\hline & Unfavorable & $\begin{array}{l}\text { talkative(19), thick-make-up(8), fat(6), ill-mannered(5), interfering(5), stubborn(5), saying-without- } \\
\text { thinking(5), brusque(5), } \operatorname{sharp}(4), \text { force(4), frivolous((3), ill-tempered(3), insincere(3), self-praise(3), } \\
\text { short-tall(2), detractive(2), nitpick(2), jealousy(2), crying-face(2) inattentive(2), dirty(2), dark-face(2), } \\
\text { skinny-person, bad-impression, masculine, choosy, unobservant, immoderate-dressed, greedy, lazy, } \\
\text { troublesome, common, dark-skin }\end{array}$ \\
\hline \multirow{2}{*}{ Female } & Favorable & $\begin{array}{l}\text { sentimental(13), good-mannered(11), good-natured(11), caring(9), humorous(8), soft(7), understanding(7), } \\
\text { bright(6) intellectual(5), true(5), clean(4), elegant(4), refined(3), look pleasing(3), benign(3), sociable(3), } \\
\text { courteous(3), hearkener(2), taciturn-person(2), lofty(2), faithful(2), plain(2), meek(2), healthy(2), smiling(2), } \\
\text { positive(2), wit, modest, active, cheerful, wise, sharp, leisurely, slim }\end{array}$ \\
\hline & Unfavorable & $\begin{array}{l}\text { snobbish(19), talkative(18), barbarian(6), ill-tempered(5), backbiting(5), offensive(4), immoderate-dress(4), } \\
\text { negligent(4), sharp(4) ugly(3), stubborn(3), selfish(3), overnice(3), narrow-minded(3), hot-temper(2), } \\
\text { rough-impression(2), silly(2), vulgar(2), strong(2), disgust(2), indecisive(2), disdainful, thoughtless, } \\
\text { greedy, negative, nagging, opportunist, obsequious }\end{array}$ \\
\hline
\end{tabular}

etc. or with other emotional terms like 'scary', 'greedy' and 'fiercetempered', etc. Seeing that respondents expressed 'beautiful' and 'looking-pleasing' when they feel favorable to the faces, and 'illtempered' when they feel unfavorable to faces, we can know that favorableness is determined by external aspects.

\subsection{Analysis of favorable styles of women in $60 \mathrm{~s}$}

The analysis of favorableness respondents in their 60 s feel to the faces of women in $60 \mathrm{~s}$ showed that both men and women favor kind and sentimental, and good-mannered styles the most, and that they generally like soft and caring styles. What the respondents like the least was talkative style. Snobbish type and women wearing thick make-up were also disliked. Men like beautiful women the most, and they also feel favorable to those who look good-mannered and pure, prosperous-looking, good-natured, sentimental, and soft. Women like sentimental style the most, followed by goodmannered, good-natured, caring, humorous, soft, and understanding styles. Male respondents pointed out that they favor the least talkative women, They also disliked women with thick make-up, fat, ill-mannered, interfering, stubborn, saying without thinking, and brusque women. Female respondents disliked snobbish women the most, followed by talkative, ill-mannered, ill-tempered, and backbiting women(Table 4).

Therefore, men and women in their 60s want women who are not talkative and who are kind and sentimental. Men, even in old ages, favor beautiful women the most, and women favor other women who have good nature and personality the most.

\section{Conclusion}

The analysis of the characteristics of emotional vocabulary which occur to the minds of respondents of 60 s who are exposed to the stimuli of facial photos of women in 60 s showed the followings. First, the proportion of positive emotional words is $37 \%$, and that of negative ones is $63 \%$, proving that respondents are likely to have negative impressions from the faces of women in $60 \mathrm{~s}$. The characteristics of words consist of $38 \%$ introversive words, $47 \%$ extraversive words, and $14 \%$ ambiversive words, showing that extraversive ones forming the plurality. Considering the study of $\operatorname{Kim}(2012)$ using respondents in 20s exposed to the facial photos of women in 60 s revealed that they expressed more negative terms than positive ones, the reason why women in 60 s give negative feeling to others seems to be derived from not bright looks of them in addition to wrinkles and dull-looking skin and blemishes caused by aging.

Second, it was found that respondents used emotional terms like 'pretty' and 'looking-pleasing' to the stimuli they felt highly favorable, and 'ill-tempered' and 'stubborn' to the stimuli they felt least favorable, which shows that people dislike women who look 'illtempered'.

Third, in the level of favorableness, both men and women favor women who are sentimental and good-mannered women the most highly, and generally favor soft, caring women. Women who are favored the least are talkative ones. Women who are snobbish and wear thick make-up are also disliked. Men favor beautiful women 
the most, and women like sentimental women the most. Men dislike talkative women the most, and women dislike snobbish ones. While men put emphasis on outward appearance of women, women emphasize mental aspects of other women. Both male and female respondents dislike talkative women. Men, even if they like beautiful women, dislike women wearing thick make-up.

In accordance with the analyses, while there may be a variety of reasons why senior citizens these days feel a lack of communication and lonely, the reasons recognized by the younger generation and by senior citizens were different in terms of the facial emotional features. For inducing more attention on the facial expression of senior citizens, relevant organizations need to promote and educate such facial expression. Next, male and female respondents showed difference in preferred style related to senior citizens. The analysis results in this paper may help image making. This paper targeted senior citizens in their $60 \mathrm{~s}$ in a restricted area. Thus, further study needs to expand the survey area to ensure more significant influence on the social life and interpersonal relationship of senior citizens.

\section{References}

Conley, J., Baker, D. C., \& Silfe, R. W. (1982). Some components and consequences of a babyface. Journal of Personality and Social Psychology, 48(2), 312-323.

Greeberg, Leslie S., \& Paivio, Sandra C. (2003). Working with Emotions in Psychotherapy. Guilford Publications.

Huh, J. H. (2000). The effects self-consciousness and stress coping strategy on positive, negative emotion. Unpublished master's thesis, Hanyang University, Seoul.

Huh, S. Y. (1995). A study on the facial expressions in Korea portrait painting focus on the Korea dynasty and early Chosun dynasty. Unpublished master's thesis, Ewha Womans University, Seoul.

Hong, B. S. (1988). A study on evaluation of the Korean and western dresses using semantic differential scales. Journal of the Korean Society of Clothing and Textiles, 12(3), 373-382.

Izzard. (1977). Human emotions. New York : Plenum.

Jo, K. D. (2004). Physical features of faces and personal personality impression. Korean Journal of the science of Emotion \& sensibility,
$7(2), 195-201$.

Kim, A. K. (2012). Analysis characteristics of image words shown on the face of woman. Fashion \& Textile Research Journal, 14(3), 465-471. doi:10.5805/KSCI.2012.14.3.465

Kim, H. S. (2003). The effects of facial impressions on face recognition. Unpublished master's thesis, Yonsei University, Seoul.

Kim, Y. A., Kim, J. K., Park, S. K., Oh, K. J., \& Jung, C. S. (1998). Dimension of the emotion structure through the analyses of emotion related terms in Korean language. Korean Journal of the Science of Emotion \& Sensibility, I(1), 145-152.

Kim, Y. J. (2002). A study of clothing formative properties in fashion sensibility and emotion. Unpublished doctoral dissertation, Busan National University, Pusan.

Kaiser, S. B. (1985). The social psychology of clothing. New York: McMillan Publishing Company.

Lee, M. Y., \& Lee, H. C. (1990). Related to affective vocabulary. Korean Journal of Cognitive and Biological Psychology, 2(1), 118-138.

Lee, K. S., \& Han, D. W. (2003). Which facial attributes of women attract young men. The Korean Journal of Social and Personality Psychology, 17(2), 73-83.

Lee, I. J., Lee, K. H., \& Shin, H. J. (2001). Clothes psychology. Seoul: Kyomunsa.

Lee, H. H., Kim, E. J., \& Lee, M. K. (2003). A validation study of Korea positive and negative affect schedule. The Korean Journal of Clinical Psychology, 22(4), 935-946.

Lee, K. Y., \& Lee, K. H. (2003). A study on female's ideal beauty based on magazine articles. The Journal of the Korean Society of Costumes, 53(8), 65-80

Oh, I. Y. (2006). The study on TV anchor's image according to the make up and hair styles. Unpublished doctoral dissertation, Kyung-Hee University. Seoul.

Park, S. J., Han, J. H., \& Chung, C. S. (2002). The analysis of physical features and affective words on facial types of Korean females in twenties. Korean Journal of Cognitive Science, 13(3), 1-10.

Park, I. J., \& Min, K. H. (2005). Making a list of Korean emotion terms and exploring dimensions underlying them. The Korean Journal of Social and Personality Psychology, 13(1), 109-129.

(Received 22 July 2014; 1st Revised 2 September 2014; 2nd Revised 17 October 2014; Accepted 20 November 2014)

Copyright (C) 2014 (by) the authors. This article is an open access article distributed under the terms and conditions of the Creative Commons Attribution license (http://creativecommons.org/licenses/by/3.0/), which permits unrestricted use, distribution, and reproduction in any medium, provided the original work is properly cited. 